\title{
Design of modern roundabouts in urban traffic systems
}

\author{
A. Pratelli \\ Dipartimento di Ingegneria Civile "Vie e Trasporti", \\ University of Pisa, Italy
}

\begin{abstract}
This paper makes an overview on modern roundabouts design and practice. Modern roundabout have become an issue of great interest over the last decade in Italy. This fact is partially drawn on the great success of roundabout traffic solutions in some European countries, where intersections design practice has changed in consequence of the performances gained with roundabouts and their general good acceptance by drivers. Modern roundabouts can have significant impacts and benefits in terms of circulation safety, delays and capacity. These quoted items form as many sections of the paper.
\end{abstract}

Keywords: modern roundabouts; priority-to-circle or offside priority; roundabout design guidelines; circulation safety; delay and capacity.

\section{Introduction}

Modern roundabouts, also called second-generation roundabouts, are based on quite different design criteria from those of traffic circles, or first generation roundabouts, built in the first half of last century. The first generation roundabouts gave priority to traffic flows entering from branches and were designed considering the weaving movements as basic goal. This way, the circles become very large, with long distances between successive branches and with relatively low speeds and circulating flows. On the contrary, modern roundabouts gave priority-to-circle and are designed for lowering speeds, with dimensions essentially defined by the number of branches, expected capacity and by the turning path of larger vehicles. The second-generation roundabouts are classified by the dimensions of their inscribed circle diameter, $D$, as follows: a) mini-roundabouts, when $D$ is less than 22 metres; b) compact roundabouts, for $D$ 
of 22 to 35-40 metres; c) large, or rural, roundabouts, when $D$ is greater than 40 metres. Mini-roundabouts are limited to applications for residential areas, while compact roundabouts are typical of urban contexts. Large roundabouts are more frequently built on suburban rings and rural highways.

One of the crucial design elements affecting safety is the effective deflection of vehicle paths through the roundabout. Entering traffic has to yield to circulating flow. At low traffic levels, vehicles usually enter without stopping, while at higher traffic levels entering flows have to wait for useful gaps in the circulating stream. Capacity can be increased flaring entry lanes and widening the circulating carriageway. The public reaction to modern roundabouts has been generally fair. This is confirmed in results of many "before-and-after" surveys showing that modern roundabouts are usually well accepted. The survey respondents mentioned the following greatest benefits: 1) shorter delays; 2) improved safety; 3) increased capacity; 4) improved aesthetics and site design. A few minor problems were mentioned, such as the advantage given to the lowtraffic branches, which sometimes causes undue delays to the major street, or the lack of clear right-of-way control for pedestrians. Safety benefits, in term of accident reductions, have been measured both in Europe and in the United States. Traffic safety benefits in general are related to the reduced speeds in the circle and also to the reduction of the number of conflict points if compared to any type of at grade intersection. Moreover, safety is supported by a more degree of responsibility of drivers caused by the slower motion and the need to concentrate on yields, as compared to the driver behaviour in signalized intersections. Total crash statistics observed in EU countries showed favourable trends and benefits seem to be greater for single-lane roundabouts in rural conditions. There are mixed impacts from the point of view of bicycle safety. Studies in the Netherlands showed reductions for bicycle accidents across the board. Whereas studies conducted in Germany highlighted increases in crashes for cases in which the bicycle lane was continued through the roundabout, but any significant changes where bicycles were in mixed traffic. For compact situations, the preferred arrangement is to end bicyclist lanes before they reach the roundabout and to let bicycle circulate in mixed traffic through the circle. For large cases, or multi-lane roundabouts, it becomes preferable to provide grade separation bike paths, or reroute cyclists, or even apply traffic lights. Some concerns were raised regarding to the absence of clear right-of-way control for pedestrians at roundabouts. This problem of perception is rooted to some extent in the general belief that signalized intersections bring the greatest safety to pedestrians. Nevertheless such a concern tends to disappear after the pedestrians have an opportunity to encounter the roundabout. Another adjoined benefit is related to the aesthetics and urban design improvements often resulting from the landscaping and sculptural elements placed in the central island. Modern roundabouts can bring a sense of place to an intersection and improve the visual quality for drivers as well as for people in general. Modern roundabouts find their most appropriate applications in existing at grade intersections with high accident rates, especially when accidents are related to left-turning or crossing movements. Other appropriate locations are intersections with limited space for 
queuing storage or where it would be expensive to provide the storage space required by a signalized solution. These cases are more frequent for intersections and interchanges near bridges and tunnels. A roundabout solution is also appropriate everywhere a change in roadway space and character is desired or required, such as to mark the entrance to an urbanized area. Currently, in Italy there are not design guidelines for modern roundabouts and it is in contrast to many European countries. The following are the most widely used secondgeneration roundabout guidelines: Geometric Design of Roundabouts from United Kingdom; SETRA and CETUR French guides for large roundabout and urban cases, respectively; VSS Swiss Roundabout Guide, specific for compact instances. The paper deals on various design issues and emphasizes some implications with circulation safety.

\section{Capacity and main features}

The offside priority rule, or priority-to-circle, implies that vehicles on the entry legs were required to yield to those already in the circle. Such a rule gives rise to queues on the entry legs but kept the roundabout's operations from reaching a stoppage of traffic flow. The offside priority rule also led to entering flow from each approach must intersect the circulating flow in a "T-intersection" type under yield control operations.

Modern roundabout capacity has been investigated and derived using two methods: the gap-acceptance theory and the empirical regression theory. The first one is widely applied in Germany, especially for unsignalized intersection design [1]. The same instances are also coped with the gap-acceptance theory by the Highway Capacity Manual, since its 1895 edition. Nevertheless, research has shown that better estimates of capacity at modern roundabouts can be obtained through the application of empirical regression theory, similar to what was firstly applied by Kimber and co-workers for roundabouts in the United Kingdom [4-6]. Most design guidelines use statistically derived linear formulas expressing the capacity of each entrance in relation to both the circulating flow and the exiting traffic on the same leg, and also to some relevant geometric parameters.

An empirical regression technique is centred on the mathematical interpretation a large number of observed data. Roughly spoken, the results are formulas giving prediction of one variable $\mathrm{Y}$ when another, or more, variable $\mathrm{X}$ changes its value. For instance, the French formula developed in late ' $80 \mathrm{~s}$ by CETUR expresses the entry capacity, $Q_{e i}$, as a linear function of the impeding flow, $Q_{g i}$ [9]. The impeding flow is a summation of circulating flow, $Q_{c i}$, and a proportion of the exiting flow, $Q_{u i}$, at the same leg $i$ :

$$
Q_{g i}=Q_{c i}+\alpha Q_{u i}
$$

where the value of coefficient $\alpha$ is related to geometric characteristics such as the width of the splitter island. If $Q_{g i} \geq 1800 \mathrm{pcph}$, the entry capacity $C_{e i}=0$, otherwise it is defined as follows: 


$$
C_{e i}=1500-5 / 6 Q_{g i}
$$

It should be emphasized that the most important factors determining the capacity of an entry are the entry width, the splitter island width and the flare, and these alone should be considered as primary design parameters. Diameter or circulation width have slight effects and their use would be wrong in order to rectify or enhance the capacity of an entry $[1,4]$.

When roundabouts are being designed it is well-practice to add one additional lane at the entry and at the circulating area. The angle at which vehicles enter the circulating area takes also an important role in roundabout operations. If vehicles enter at an angle close to $90^{\circ}$ to the circulating flow then vehicles are liable to stop quickly on entry causing rear end collisions. Should they however enter at a smaller angle, approaching $10 \div 60^{\circ}$, then driver must look over their shoulders in an attempt to merge.

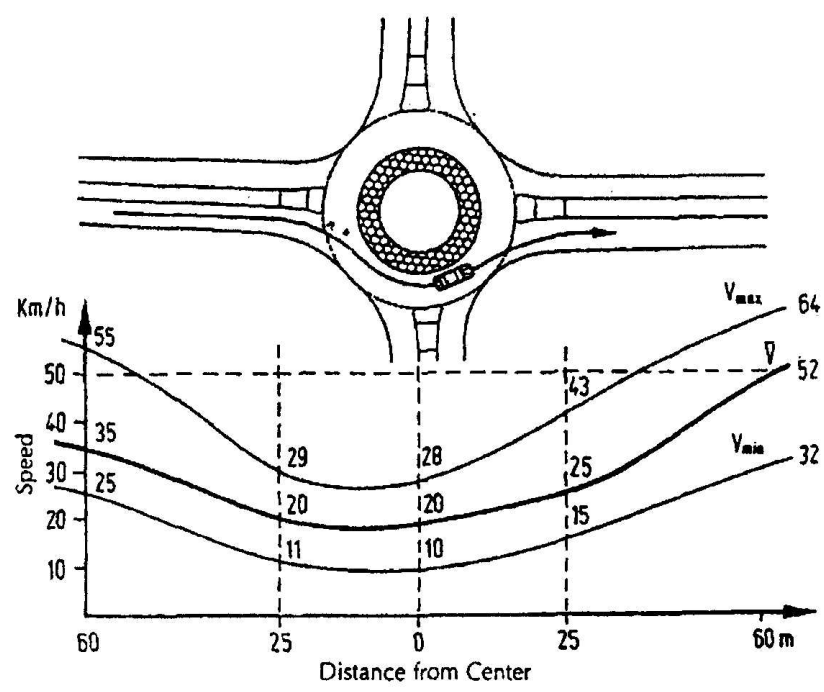

Figure 1: Safety aspects of roundabouts: slowing down of the vehicle speeds observed in a German roundabout with $26 \mathrm{~m}$ inscribed diameter [2].

Safety at roundabouts is enhanced by limiting circulating speeds and this is achieved by entry path deflection, which is a measure of the vehicle path curvature to its right (or left for UK-like drivers) side imposed on vehicles entering the circulating area. The entry deflection forces all drivers to slow down, so that conflicts are normally avoided and accident probabilities are greatly reduced. The fact that all vehicles travel at low speeds and at very low relative speeds, makes driving operation more suitable and improves safety. For example, the average speed in the inner circulation area of a compact roundabout is about $20 \mathrm{kmph}$ (see Fig. 1). To meet effective deflection requirements it is 
usually recommend that the entry path curvature should not greater than $100 \mathrm{~m}$ to prevent vehicles from passing through the circle unimpeded. It often happens that the entry path deflection is more difficult to design for a roundabout solving a $\mathrm{T}$-junction than for cases with four or more legs.

The guidance conditions and the separation of the various movements by the splitter islands and the central island reduce the number of conflict points. For instance, Figure 2 shows that whereas a typical four-way intersection has a total of 32 possible conflict points, a four-leg roundabout has only eight possible conflict points $[2,3,7]$.

Traffic operations at modern roundabouts compared to signalized intersections decrease the level of stress and aggressiveness of drivers. Having to yield to the traffic in the circle and having to slow down induces a greater sense of responsibility, in opposition to driving at higher speeds through a signalized intersection or crossing an uncontrolled intersection. A driver facing a green light feels more empowered than a driver engaging in a yield cross line [3].

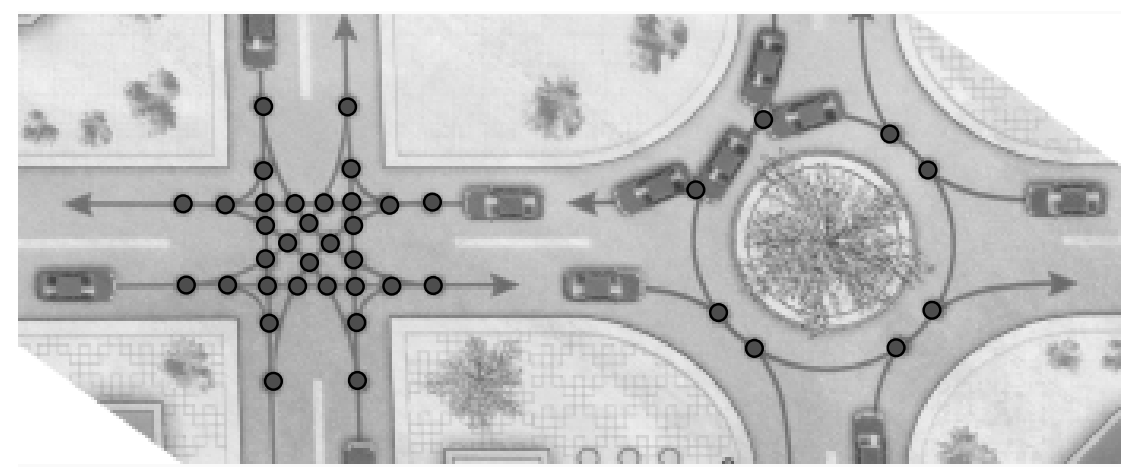

Figure 2: $\quad$ Safety aspects of roundabouts: a four-legged roundabout shows only 8 conflict points, instead 32 conflict points observed in a four-way intersection.

\section{Delays and queues}

Roundabout delay has received less attention from researchers as compared to roundabout capacity. Gardner made a before-and-after study to compare the effect of converting intersection control from a two-way stop to a roundabout [13]. The results showed that the conversion to a roundabout caused a reduction of the minor street average delay by about $83 \%$ in the morning peak and by $76 \%$ in the afternoon peak. On behalf of our personal experience, we have recently designed a compact roundabout that substituted a previously signalized intersection on SR222 Highway at Ponte a Ema, Florence (Italy). Average delays decreased substantially, as showed in Table 1 comparing the values per vehicle obtained during the morning peak. Kimber and Hollis developed a comprehensive research on traffic delay and queues at intersections in Great 
Britain [5]. They estimated vehicle delay as a function of entry capacity, entry degree of saturation, and distribution of arrivals and traffic gaps, assuming that vehicles enter the roundabout based on the gap acceptance concept.

Although the correspondence noted help to clarify the connection between some roundabout situations and other uncontrolled intersection problems, they are all fairly remote from normal roundabout operations. The feature of giving priority to vehicles already into the circle creates a resemblance between queueing theory models for a roundabout and those for uncontrolled intersection at which one stream of traffic have absolute priority. Nevertheless, the fact that the road with priority loops back on itself in a relative short distance makes the roundabout rather different from a stretch of linear priority roadway with successive intersections with minor roads.

For instance, Troutbeck and Kako [14] observed that circulating stream vehicles were sometimes forced to slow down slightly to accommodate entering vehicles and called this phenomenon as "gap-forcing behaviour". They studied the effect of gap-forcing behaviour and concluded that the headways in the circulating stream could be slightly increased as the result of merging flow entering, especially under saturated conditions. The proposed gap-acceptance model with "limited priority" to account for the gap-forcing behaviour was found very close to the empirical relationship established by Kimber [3].

Table 1: $\quad$ Before and after calculated entry average delays during morning peak hour on SR222 highway intersection at Ponte a Ema, Florence (Italy).

\begin{tabular}{|l|c|c|c|c|}
\hline \multicolumn{1}{|c|}{ entry } & $t_{w}$ signal & $t_{w}$ roundabout & $\Delta(\mathrm{secs})$ & $\Delta \%$ \\
\hline 1) SR222 (Fi) & 26,7 & 9,6 & $-17,1$ & $-64 \%$ \\
\hline 2) Ponte a Ema & 55,8 & 11,7 & $-44,1$ & $-79 \%$ \\
\hline 3) SR222 (Grass.) & 13,9 & 9,6 & $-4,3$ & $-31 \%$ \\
\hline 4) Zona Art. & 68,9 & 8,7 & $-60,2$ & $-87 \%$ \\
\hline
\end{tabular}

On the side of regression analysis methodologies one can quote the following relationship proposed by Swiss Guidelines [3] for urban roundabouts with inscribed diameter $D$ of 25 to $40 \mathrm{~m}$ :

$$
t_{w i}=\frac{2000+2 Q_{c i}}{C_{e i}-Q_{e i}}
$$

where: $t_{w i}$ is the entry average delay; $Q_{c i}$ and $Q_{e i}$ are the circulating flow and the entering flow, respectively; $C_{e i}$ is the entry capacity, given by:

$$
C_{e i}=\lambda\left(A-\beta Q_{c i}\right)
$$

where: $\lambda=1$ and $A=1450$ for a single-lane entry and $Q_{e i}$ greater than $1000 \mathrm{pcph}$, otherwise $A=1300$; while $\lambda=1,4$ for a two-lane entry. 
Once solved for (3), an estimation of $90^{\text {th }}$ percentile of queue length, $L_{90}$, is simply obtained by:

$$
L_{90}=2 \delta Q_{e i} t_{w i}
$$

where $\delta$ is usually assumed equal 6 to obtain $L_{90}$ in meters.

\section{Safety benefits}

Roundabouts are worldwide considered an excellent way for improving traffic safety. Many technical reports stated that the average accident risk at a roundabout is approximately $30 \%$ less than that at all other conventional crossroads or T-junction, with or without traffic signals $[1,2,10]$.

Based on a before-and-after study conducted ten years ago in the Netherlands (see Table 2) it can be stated that compact roundabouts are likely to have at least $45 \%$ lower accident risks than conventional intersections [10].

Table 2: Average annual crashes frequencies before and after urban roundabout construction in the Netherlands [10].

\begin{tabular}{lccc}
\hline & Before roundabout & After roundabout & $\Delta \%$ \\
\hline Total crashes & 4,9 & 2,4 & -51 \\
\hline Injuries & 1,3 & 0,37 & -72 \\
\hline Two-wheel injuries & 0,55 & 0,31 & -44 \\
\hline
\end{tabular}

A study conducted in the year 1988 in France analyzed the safety record at 522 roundabouts with an average daily traffic of about 12500 vehicles [15]. The $90 \%$ of these monitored roundabouts had no injury accidents at all, while the injury crash rates per roundabout for the same year are listed in Table 3. About $25 \%$ of injuries were classified as serious and $75 \%$ as light. Moreover, the study fond that also the number of crashes involving bicycles was lower than for signalized intersections, even if that reduction was less than for other motorized vehicles.

Another French study of 83 observed instances found that roundabouts with smaller inscribed diameters have fewer crash frequencies than larger roundabouts or those with elliptic shapes [11]. Table 4 resumes these findings.

Table 3: $\quad$ Crash frequencies observed for 522 roundabouts in France [15].

\begin{tabular}{lc}
\hline & Frequency per roundabout \\
\hline Injury crashes & 0,15 \\
\hline Fatalities & 0,01 \\
\hline Injuries & 0,20 \\
\hline
\end{tabular}


On behalf of his before-and-after observations on modern roundabouts in Germany, Brilon and co-workers state that the number of pedestrian accidents decreased of four time. Particularly, roundabouts provide an adequate degree of safety for pedestrian when there are splitter islands between the entrance and the exit lanes of different branches providing a haven buffer. Moreover, crosswalks should placed no far 6 to 8 meters back from the edge of the roundabout. This location allows conflicts with approaching vehicles at lowest speeds and with exiting vehicles at beginning of acceleration.

On the contrary, cyclists do not take advantages at roundabouts of the same extent as pedestrian. Although bicycles traversing a well-designed roundabout do not incur in safety hazards, even as compared with conventional intersections, design errors contribute to negative impacts on safety for cyclists. For instance, the study by Alphand et al [15] showed that for 15 towns in the west of France, the annual frequency of two-wheel vehicle accidents at signalized intersections was 0,23 in opposition with 0,13 per year per roundabout. Single-lane compact roundabouts are usually safer, because bicycle speeds are fairly near to the lowered vehicle speeds. Moreover, vehicles seldom overtake bicycles, then cyclists are able to make clear their intended path.

Table 4: $\quad$ Crash frequencies and size of the inscribed diameter [11].

\begin{tabular}{ccc}
\hline Size of inscribed diameter & $\begin{array}{c}\text { Number of } \\
\text { roundabouts }\end{array}$ & $\begin{array}{c}\text { Crashes per roundabouts } \\
\text { per year }\end{array}$ \\
\hline$<30 \mathrm{~m}$ & 13 & 0,69 \\
\hline $30-50 \mathrm{~m}$ & 11 & 1,54 \\
\hline $50-70 \mathrm{~m}$ & 26 & 1,58 \\
\hline $70-90 \mathrm{~m}$ & 16 & 1,81 \\
\hline$>90 \mathrm{~m}$ & 8 & 3,80 \\
\hline Oval shape & 9 & 4,40 \\
\hline
\end{tabular}

These facts are not true for larger roundabouts, whose tend to be more dangerous for bicycles since motorized vehicles have higher speeds and often follow different and conflicting trajectories. German practice have highlighted dangerousness of separate cycle lanes placed through only marking signs on the outer edge of the roundabout [1]. If separate bikeways are to be provided they should be designed outside the circle with branch crossings jointed to the pedestrian crosswalks.

\section{Public opinion}

Despite construction of modern roundabouts can substantially reduce accidents and consequently enhance traffic safety and road environment, up to today it sometimes has encountered a considerable obstacle from local residents to the conversion of specific intersections from stop sign or signal controlled to modern roundabout. 
Fortunately, some local administrations have built roundabouts in spite of such public opposition. In the following is showed some instances of anecdotal evidence suggesting that public opinion generally changes from ex-ante diffidence to generalized acceptance ex-post. Roughly speaking, public acceptance increases dramatically once local residents have been adapted their behaviour to this new form of traffic facility. There are no formal studies on specific reasons leading to such misperception by drivers unfamiliar with roundabouts. Nevertheless, one can quote some sample results (see Table 5) collected on a sample of U.S. communities [12].

Table 5: $\quad$ Percent of respondents in favour of/opposed to roundabouts B-\&-A surveys in U.S.A. (sample $n=300$ per city per time ) [12].

\begin{tabular}{lcccccccc}
\hline & \multicolumn{2}{c}{ KANSAS } & \multicolumn{2}{c}{ MARYLAND } & \multicolumn{2}{c}{ NEVADA } & \multicolumn{2}{c}{ Total } \\
\cline { 2 - 9 } & Bef. & Aft. & Bef. & Aft. & Bef. & Aft. & Bef. & After \\
\hline Strongly favour & 9 & 31 & 15 & 29 & 23 & 37 & 16 & 32 \\
\hline Somewhat favour & 13 & 29 & 11 & 34 & 21 & 30 & 15 & 31 \\
\hline Somewhat oppose & 16 & 15 & 14 & 14 & 12 & 11 & 14 & 13 \\
\hline Strongly oppose & 44 & 15 & 51 & 18 & 26 & 11 & 41 & 15 \\
\hline Don't know & 17 & 10 & 8 & 5 & 18 & 12 & 14 & 9 \\
\hline
\end{tabular}

Table 6: Expected performances of Querciola roundabout update project in Sesto Fiorentino, Florence (Italy).

\begin{tabular}{|l|l|l|c|}
\hline Entry & \multicolumn{1}{|c|}{ Actual } & \multicolumn{1}{c|}{ Project } & \multicolumn{1}{c|}{ Change } \\
\hline \multirow{5}{*}{ 1) Via Togliatti } & $t_{w}=51 \mathrm{secs}$ & $t_{w}=6,5 \mathrm{secs}$ & $-87 \%$ \\
\cline { 2 - 4 } & $L_{95}>180 \mathrm{~m}$ & $L_{95} \leq 42 \mathrm{~m}$ & $-77 \%$ (min.) \\
\cline { 2 - 4 } & $C_{\mathrm{e}}=983 \mathrm{pcph}$ & $C_{\mathrm{e}}=1549 \mathrm{pcph}$ & $+58 \%$ \\
\hline \multirow{5}{*}{ 2) Via Querciola (sud) } & $t_{w}=6 \mathrm{secs}$ & $t_{w}=3,5 \mathrm{secs}$ & $-42 \%$ \\
\cline { 2 - 4 } & $L_{95}=12 \mathrm{~m}$ & $L_{95}=12 \mathrm{~m}$ & $0 \%$ \\
\cline { 2 - 4 } & $C_{\mathrm{e}}=615 \mathrm{pcph}$ & $C_{\mathrm{e}}=1048 \mathrm{pcph}$ & $+70 \%$ \\
\hline \multirow{5}{*}{ 3) Viale Ariosto } & $t_{w}>60 \mathrm{secs}$ & $t_{w}=19 \mathrm{secs}$ & $-68 \%(\mathrm{~min})$. \\
\cline { 2 - 4 } & $L_{95}>180 \mathrm{~m}$ & $L_{95}=150 \mathrm{~m}$ & $-17 \%(\mathrm{~min})$. \\
\cline { 2 - 4 } & $C_{\mathrm{e}}=1329 \mathrm{pcph}$ & $C_{\mathrm{e}}=1658 \mathrm{pcph}$ & $+25 \%$ \\
\hline 4) Via Querciola (nord) & $t_{w}=42 \mathrm{secs}$ & $t_{w}=5,5 \mathrm{secs}$ & $-87 \%$ \\
\cline { 2 - 4 } & $L_{95}=84 \mathrm{~m}$ & $L_{95}=30 \mathrm{~m}$ & $+79 \%$ \\
\cline { 2 - 4 } & $C_{\mathrm{e}}=582 \mathrm{pcph}$ & $C_{\mathrm{e}}=1040 \mathrm{pcph}$ & \\
\hline
\end{tabular}

But it is the same the whole world over: only last year 2005 we encountered a soft opposition from residents to our project related to upgrading an old 4-arm large roundabout with $54 \mathrm{~m}$ inscribed diameter - born under priority-to-arms rule 
- in Bagno a Ripoli, Florence (Italy). One can see Table 6 showing the calculated (via French formulas by SETRA [8]) before-and-after expected performances and we are obviously pleased because the local Administration started construction works at the beginning of the current year.

\section{Conclusions}

Based on worldwide applications and experiences, modern roundabouts have many advantages if compared to conventional stop sign or signal controlled intersections. These advantages span from capacity enhancements to traffic safety increases. This last is also extended to pedestrian and cyclists accommodation, even if special devices occur. Modern roundabouts can be used to realize efficient traffic flows, with low delays and a reduced risk level of accidents. Construction and maintenance costs are usually low as a consequence of the need of limited space and the absence of traffic control apparatuses.

All these features jointly with a general amount of positive experiences have conferred the popular and enthusiastic interest for modern roundabout, firstly in Europe and Australia and more recently in North America.

However, quoting Brilon [1], the effective success of roundabouts relies heavily on carefully following the design guidelines and thorough an analysis of the likely operations characteristics to ensure the adequate capacity will be available to better accommodate traffic demands.

\section{References}

[1] Brilon W., Vandehey M., Roundabouts - The state of the art in Germany". ITE Journal, Nov., pp. 48-54, 1988.

[2] Transportation Research Board, Modern roundabout practice in the United States. NCHRP Synthesis 264, Washington 1998.

[3] VSS, Guide Suisse des giratoires. Institut des Transports et de Planification, Lausanne 1991.

[4] Glen M., Summer S., Kimber R., The capacity of offside priority roundabout entries. TRRL Supplementary Report 436, Crowthorne 1978.

[5] Kimber R., Hollis E., Traffic queues and delays at road junctions. TRRL Report 909, Crowthorne 1979.

[6] Kimber R., The traffic capacity of roundabouts. TRRL Report 942, Crowthorne 1980.

[7] Pratelli A., Progetto delle intersezioni a rotatoria, T.E.P., Pisa 2001.

[8] Service d'Études Techniques des Routes et Autoroutes - SETRA, Capacité des carrefours giratoires interurbains, premiers résultats. Note d'information n. 44, Bagneux 1987.

[9] Centre d'Études des Transports Urbains - CETUR Conception des carrefours à sens giratoire implantés en milieu urbain. Bagneux 1988.

[10] Schoon C., Van Minnen J., The safety of roundabouts in the Netherlands. SWOV Institute for Road Safety Research, Traffic Engineering and Control, 1994. 
[11] Centre d'Etudes Techniques de l'Equipement de 1'Ouest, Evolution de la sécurité sur les carrefours giratoires. Nantes 1986.

[12] Retting R., Luttrell G., Russell E., Public opinion and traffic flow impacts of newly installed modern roundabouts in the United States". ITE Journal, Sept., pp. 30-37, 2002.

[13] Gardner P., Little Falls, Gorham reconstruction to a modern roundabout. Transportation Research Record 1658, TRB, pp. 17-24, 1999.

[14] Troutbeck R.J. and Kako S., Limited priority merge at unsignalized intersections. Proceed. Of the Third Int. Symp. on Intersections Without Signals, Portland, pp. 294-302, 1997.

[15] Alphand L. et al., Roundabouts and road safety, state of the art in France. in Brilon W. (ed.) Intersections without Traffic Signals II, SpringerVerlag, pp. 107-125, 1991. 